\title{
Numerical analysis of the state of stress and strain in the Yenisei Ridge based on the regional tectonic state in the Asian continent
}

\author{
Ayan Zh. Akhmetov, Igor Yu. Smolin, Aleksey Yu. Peryshkin \\ Tomsk State University, Institute of Strength Physics and Materials Science SB RAS, Russia \\ ayan.akhmetov93@gmail.com,bttp://orcid.org/0000-0001-8077-7175 \\ smolin@ispms.ru, bttp://orcid.org/0000-0003-3167-9530 \\ alexb700@yandex.ru, bttp://orcid.org/0000-0002-4114-0718
}

\begin{abstract}
The paper presents the calculation of modern tectonic flow fields in the Yenisei Ridge located on the stable Siberian Craton. At the first stage, we solve the problem of calculating the average field of tectonic flows due to collisional processes at the southern and northeastern margins of the Eurasian Plate with Indian and Arabian and with North American plates, respectively. These calculations clarify the state of stress and the structure of tectonic flows on the territory of the Siberian Craton. The subtraction of the average displacements of the Siberian Craton as a whole in the northeast direction reveals the detailed structure of tectonic flows. Structural models are built along the Batolit-1982 and Shpat geological profiles crossing the Yenisei Ridge. At the second stage, we numerically study the state of stress and strain along these profiles determined by the global tectonics of Central and Southeast Asia, as well as their structural organization and interaction with the neighboring crustal elements.
\end{abstract}

KEYwORDs. Tectonic flow; Collision; Geological cross-section; State of stress and strain; Numerical modeling.

\section{OPEN ACCESS}

Citation: Akhmetov A.Zh.., Smolin I.Yu., Peryshkin A.Yu., Numerical analysis of the state of stress and strain in the Yenisei Ridge based on the regional tectonic state in the Asian continent, Frattura ed Integrità Strutturale, 49 (2019) 190-200.

Received: 10.04 .2019

Accepted: 20.05 .2019

Published: 01.07.2019

Copyright: (C) 2019 This is an open access article under the terms of the CC-BY 4.0, which permits unrestricted use, distribution, and reproduction in any medium, provided the original author and source are credited.

\section{INTRODUCTION}

$\mathrm{T}$ he Earth's crust motion, as well as the main geodynamic processes such as collision, subduction, and spreading, is studied on the basis of the concept of plate tectonics that originated from Wegener's revolutionary ideas [1].

Tectonics of the large Eurasian Plate and especially tectonic processes in Central and Southeast Asia, being its most dynamic parts, attract the close attention of many scientists. These regions demonstrate all the variety of tectonic processes. They contain seismically active intracontinental rifts, for example, the Red River Rift (China) and the Baikal Rift Zone (Russian Federation).

A special role in the formation of tectonic flows in Central and Southeast Asia is played by the Indian subduction caused by the collision between the Eurasian and Indian plates [2]. This collision results in the formation of the Tibetan Plateau and the Pamir and Himalayan mountains. The tectonic pattern of the Asian continent is also affected by the collision 
between the American and Eurasian plates in the northeast with the formation of the Verkhoyansk Range and the Kolyma Mountains [3]. With the 300 million year evolution of tectonic transformations in Asia, from the division of Pangea into Gondwana and Laurasia to the formation of modern Asian mountain systems, the global pattern of plate motion plays a minimal role in the study of regional tectonic flow and is used only to evaluate initial and boundary conditions in the studied area [2-4].

A significant part of Northern Eurasia is occupied by the Siberian Craton, which is one of the largest Archean-Proterozoic regions. Its structure is very heterogeneous and includes Archean-Paleoproterozoic belts separated by suture zones. Geographically, the Siberian Craton is bounded by the West Siberian fold system in the west, by the VerkhoyanskChukotka mesozoic folded structures in the east, by the North American Plate in the northeast, and by the Baikal fold system in the south [5], thus being adjacent to the intracontinental Baikal Rift.

One of the interesting regions of the Siberian Craton in respect to the study of the Asian continent history is the Yenisei Ridge, which includes Paleoproterozoic, Mesoproterozoic and Neoproterozoic igneous and metamorphic rocks [6]. The Yenisei Ridge located along the Yenisei River is the main structural feature of the western margin between the Siberian Craton and the Central Asian fold belt. It is also referred to as an accretion-collision orogen distinguished by the geological and geophysical data of the Siberian Craton in the east and of the West Siberian Plate in the west. The structure of the Yenisei Ridge includes numerous terranes separated by faults [7]. Therefore, the interpretation of its tectonic structure and formation conditions is necessary for the analysis of regional and global geodynamic reconstructions of the Eurasian lithosphere.

With the computer development, it became possible to model global and regional tectonic flows of the Earth's crust. Using them as data on geophysical, geochemical, and geotectonic structures of the Earth's crust, Müller et al. designed a computer program that models global geodynamic phenomena [8]. However, it runs into difficulties when studying regional tectonic flows. To analyze both global and regional geotectonic flows in the Asian continent, a new methodology was proposed, which combines methods of solid mechanics and nonlinear dynamic and allows a description of tectonic flows and deformation as a typical evolutionary process essentially heterogeneous in space and time $[9,10]$. This makes it possible to investigate the global pattern of tectonic flows and the stress-strain state in the Asian continent in a twodimensional formulation. However, features of vertical movements and the volumetric stress state in the Earth's crust cannot be found within this approach.

The aim of this work is to carry out numerical investigations and to analyze the regional geotectonic pattern in the Yenisei Ridge as a result of the evolution of the stress-strain state and tectonic flows in Central Asia due to the collision of the Eurasian continent with Hindustan and Arabia in the south and with North America in the northeast. At the next stage, we analyze features of the state of stress and strain in the deep structure of the Yenisei Ridge. These aims are attained using the general tectonic pattern in the Asian continent, the regional tectonic state of the Siberian Craton, and the data of the Batolit-1982 and Shpat geological profiles.

\section{Problem STAtement}

o analyze tectonic flows in Central and Southeast Asia on the whole and in the Siberian Craton, we develop a structural model of this region of the Asian continent (Fig. 1b) using Seminskii's scheme of the zone-block lithospheric structure of the Central and East Asia (Fig. 1a) [11]. This model includes specially introduced boundary blocks that allow reproducing real geodynamic effects produced by the neighboring regions.

Such a structural model of the Asian continent is two-dimensional and gives only a two-dimensional pattern of geotectonic flows for modeling. To analyze features of the state of stress and strain of the Yenisei Ridge with consideration for deep crustal structures, structural models of vertical cross-sections of the Earth's crust are developed with the use of the Batolit-1982 and Shpat geological profiles [4] obtained by the deep seismic sounding method. Their orientation is shown in Figure 2.

Structural parts of the deep seismic cross-sections of the Yenisei Ridge along these profiles are illustrated in Fig. 3.

These data allow us to design computer structural models of the chosen areas of the Yenisei Ridge (Fig. 4). The profiles include tectonic faults of different types, which are modeled in the form of weakened zones at the edges of these faults.

The P- and S-wave velocities shown in Fig. 3 are used to calculate elastic properties of each layer of the structural models. They are listed in Tables 1 and 2 [4]. 


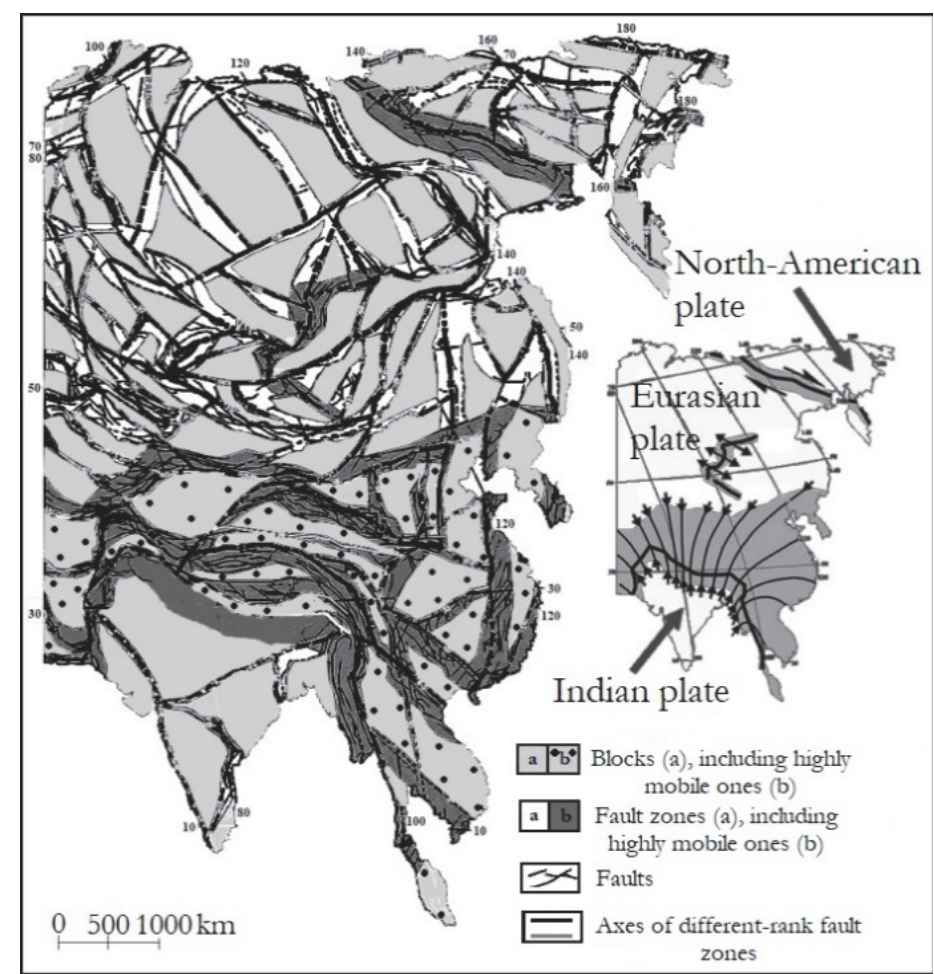

(a)

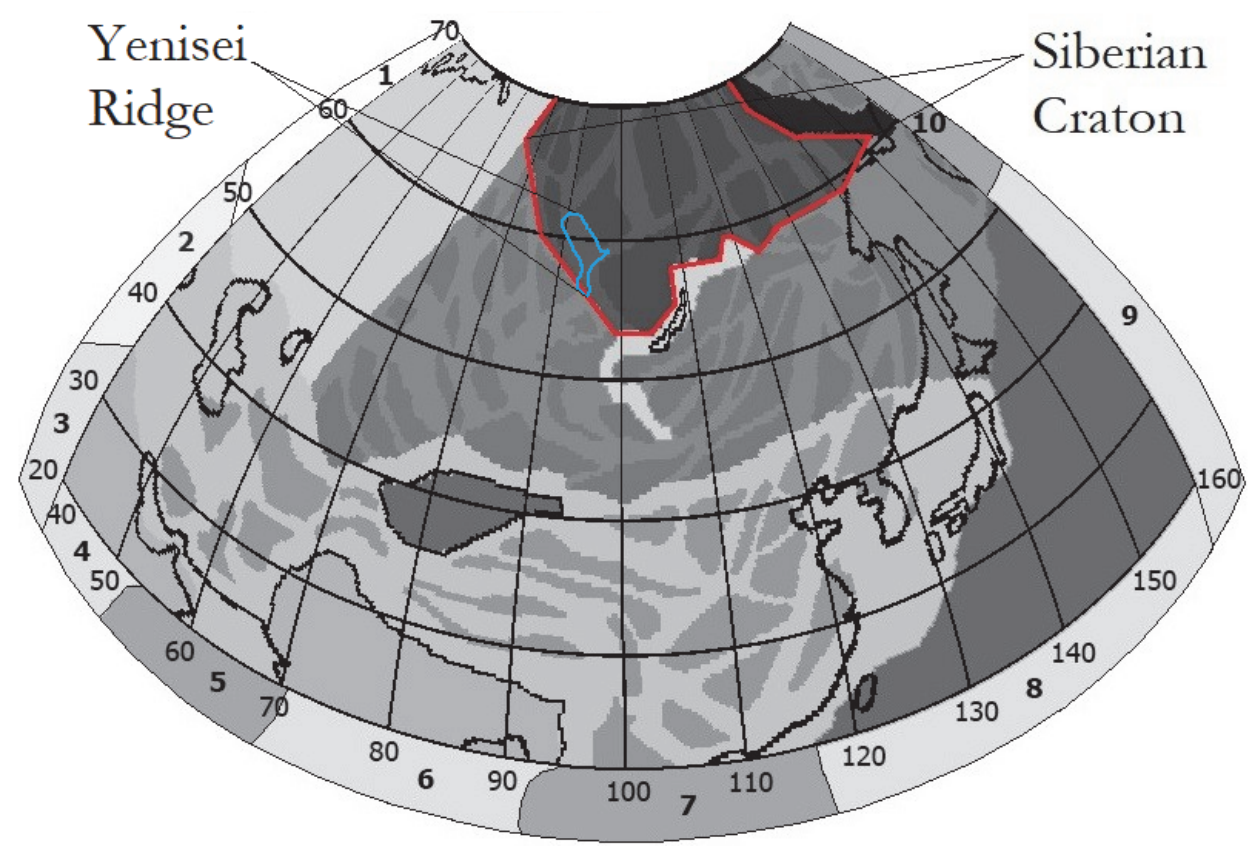

(b)

Figure 1: Seminskii's scheme of the zone-block lithospheric structure of Central and East Asia (a); map of the computational domain with the three groups of zone-block regions and boundary elastic blocks (b). 


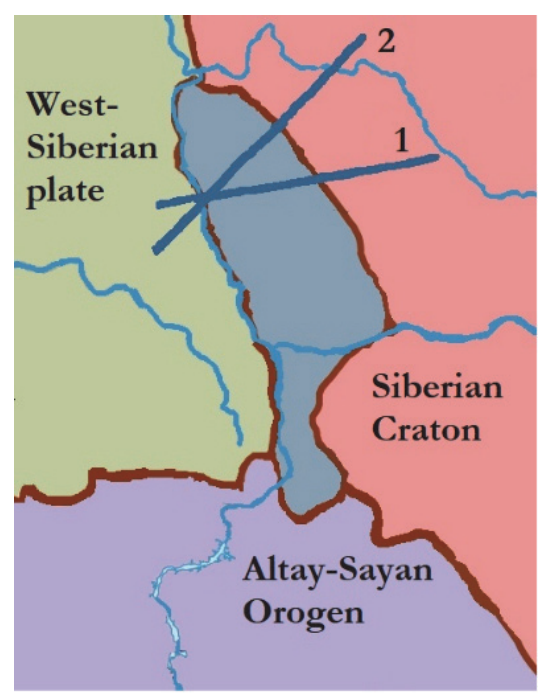

Figure 2: Orientation of the (1) Batolit-1982 and (2) Shpat geological profiles crossing the Yenisei Ridge.

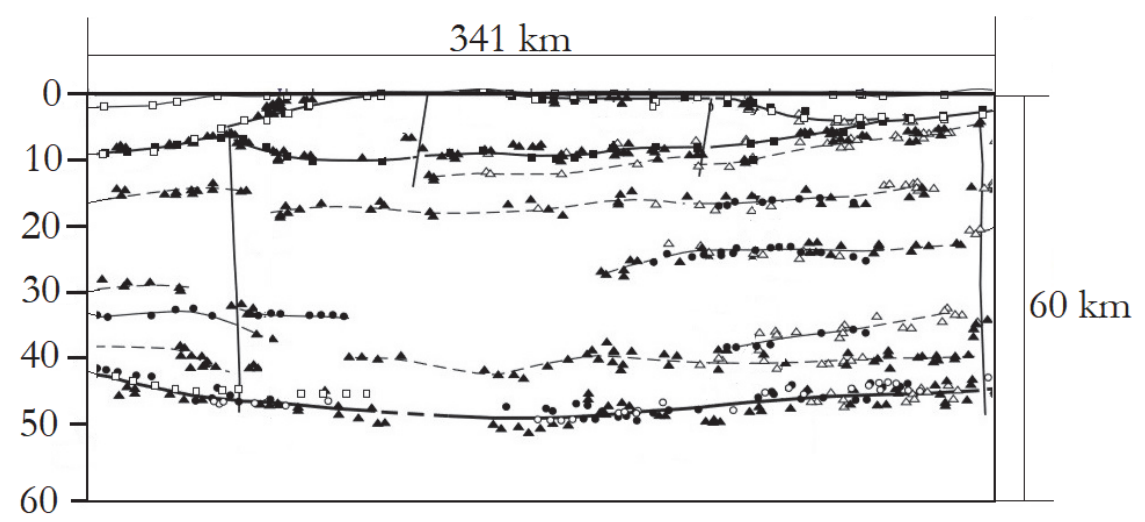

(a)

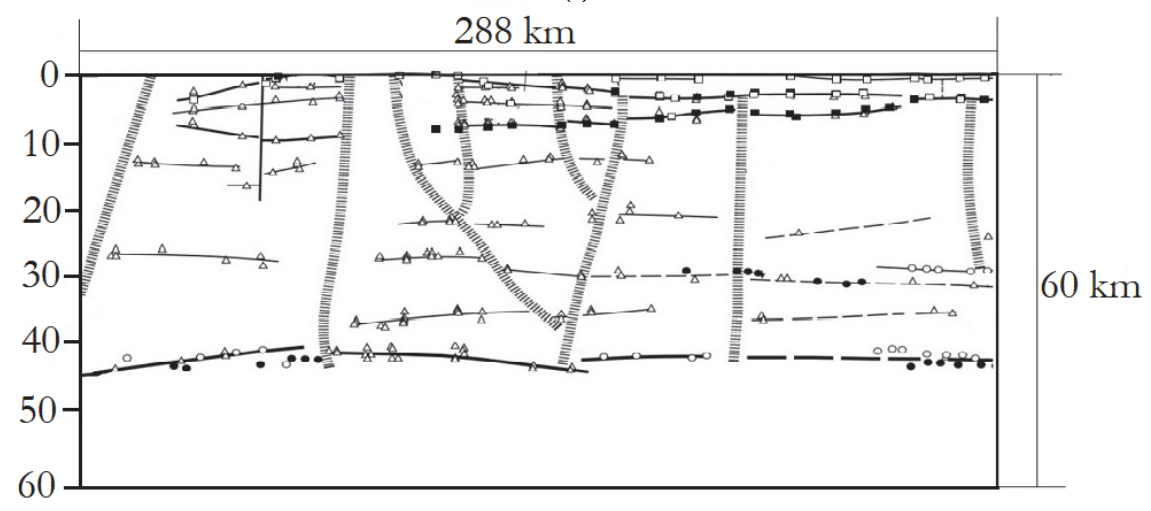

(b)

Figure 3: Structural models of deep layers of the Yenisei Ridge along the (a) Batolit-1982 and (b) Shpat profiles.

These profiles reveal crustal layers and a 10-12 km deep lens in the Yenisei Ridge with different geological, physical and mechanical properties. 

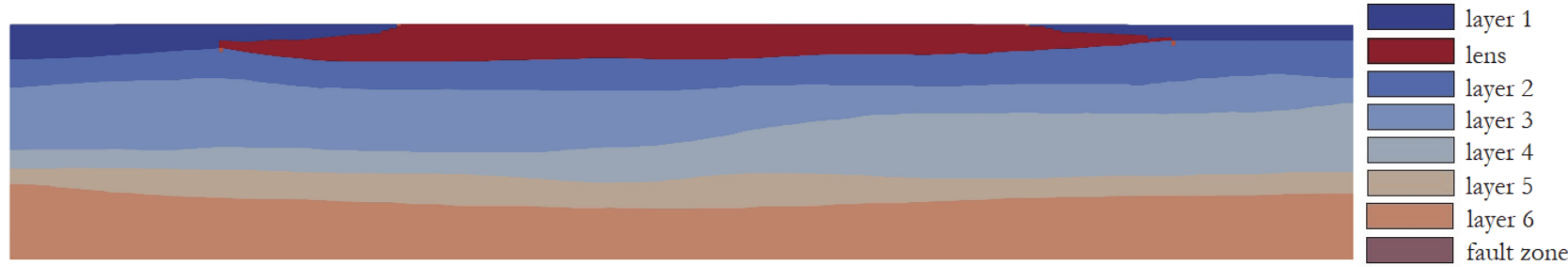

(a)
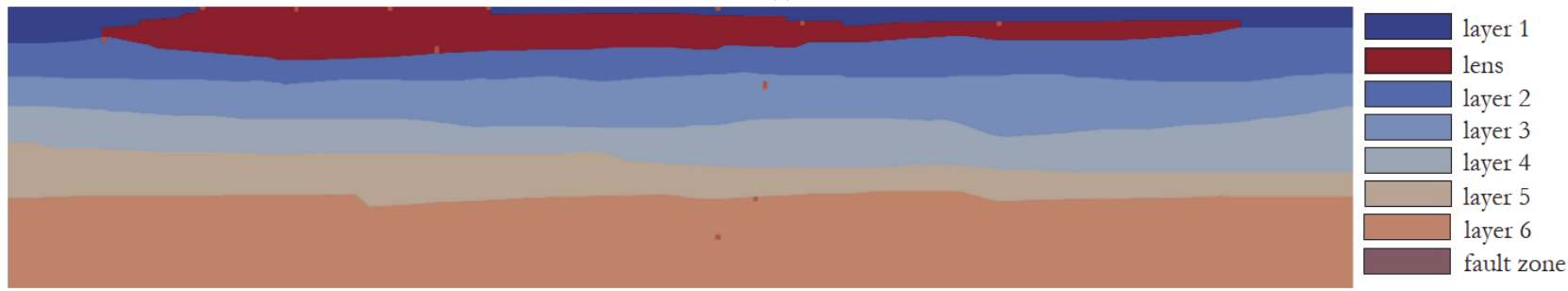

(ธ)

Figure 4: Computer models of the Yenisei Ridge based on the (a) Batolit-1982 and (b) Shpat geological profiles.

\begin{tabular}{|c|c|c|c|c|c|c|c|c|}
\hline & Layer 1 & Layer 2 & Layer 3 & Layer 4 & Layer 5 & Layer 6 & Lens & Faults \\
\hline Density $\left(\mathrm{g} / \mathrm{cm}^{3}\right)$ & 2.68 & 2.78 & 2.81 & 2.93 & 3.05 & 3.25 & 2.30 & 2.00 \\
\hline $\begin{array}{l}\text { Bulk modulus of } \\
\text { elasticity }(\mathrm{GPa})\end{array}$ & 52.22 & 58.73 & 63.12 & 66.07 & 66.57 & 78.73 & 50.00 & 45.00 \\
\hline Shear modulus (GPa) & 33.67 & 35.43 & 36.52 & 41.64 & 46.98 & 44.25 & 28.80 & 25.45 \\
\hline
\end{tabular}

Table 1: Elastic properties of the crustal layers of the Yenisei Ridge along the Batolit-1982 profile.

\begin{tabular}{lllllllll}
\hline & Layer 1 & Layer 2 & Layer 3 & Layer 4 & Layer 5 & Layer 6 & Lens & Faults \\
Density $\left(\mathrm{g} / \mathrm{cm}^{3}\right)$ & 2.71 & 2.75 & 2.92 & 2.95 & 3.02 & 3.25 & 2.30 & 2.00 \\
$\begin{array}{l}\text { Bulk modulus of } \\
\text { elasticity }(\mathrm{GPa})\end{array}$ & 53.28 & 61.69 & 67.20 & 67.68 & 80.35 & 75.16 & 50.00 & 45.00 \\
\begin{tabular}{l} 
Shear modulus $(\mathrm{GPa})$ \\
\hline
\end{tabular} & 33.33 & 36.64 & 38.65 & 39.30 & 53.27 & 46.93 & 28.80 & 25.45 \\
\hline
\end{tabular}

Table 2: Elastic properties of the crustal layers of the Yenisei Ridge along the Shpat profile.

Strength properties of elements of the Earth's crust and upper mantle are difficult to determine due to the lack of reliable information on deep, and therefore inaccessible, layers of the Earth. Various models of the depth variation of the geomedium strength are proposed.

It is known that the geomedium strength depends on the pressure and using the Drucker-Prager criterion can be represented as $[12,13]$

$$
\sigma=Y+\alpha \cdot P
$$

where $Y$ is the shear strength at zero pressure (cohesion);

$\alpha$ is the friction angle;

$P$ is the pressure.

The depth dependence of the geomedium strength is often taken for continental plates in the form shown in Fig. 5 [1214]. In order to obtain the pressure-depth dependence with consideration for Eq. (1), values of shear strength and friction angle are chosen as a function of depth. 


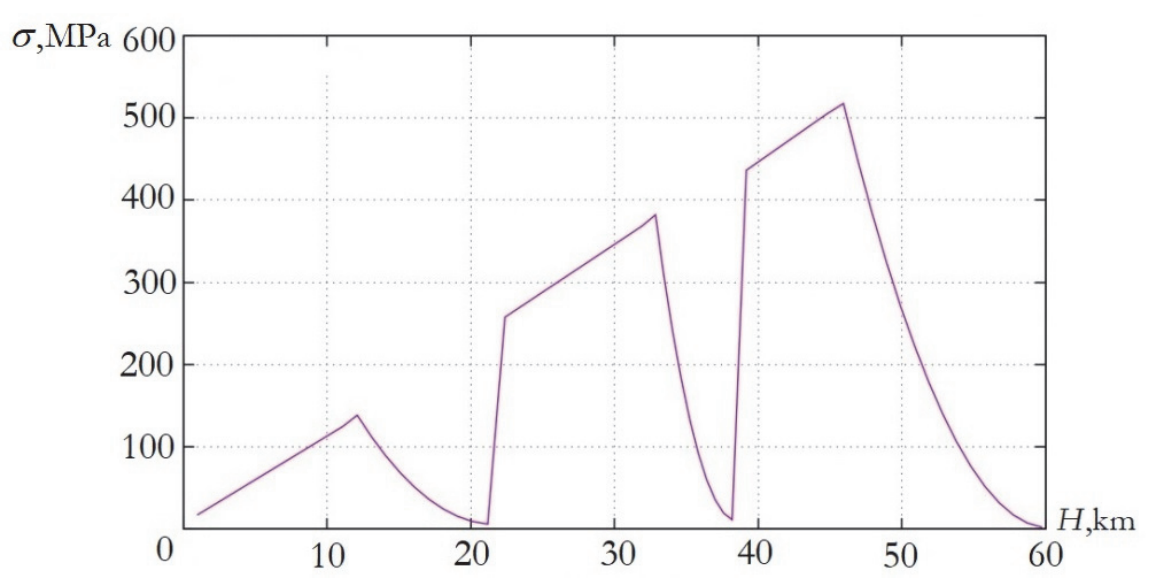

Figure 5: Strength of the geomedium layers as a function of depth.

\section{MATHEMATICAL MODEL}

he description of continuum deformation includes the set of following equations: fundamental conservation laws and constitutive relations.

Fundamental conservation laws:

$$
\begin{array}{ll}
\text { - Mass } & \frac{d \rho}{d t}+\rho \dot{u}_{i, i}=0 \\
\text { - Impulse } & \rho \ddot{u}_{i}=\sigma_{i j, j}+\rho g_{i} \\
\text { - Energy } & \dot{E}=\sigma_{i j} \dot{\varepsilon}_{i j}
\end{array}
$$

Here $\rho$ is the material density, $u_{i}$ is the i-component of the displacement vector, $\sigma_{i j}$ is the stress tensor components, $g_{i}$ Fis the i-component of the gravity acceleration, $E$ is the internal energy, $\varepsilon_{i j}$ is the strain tensor component.

The constitutive equations of the first group are written down in the rate form (5)-(6) in which the stress rate is proportional to elastic strain rate $\dot{\varepsilon}_{i j}^{e}=\dot{\varepsilon}_{i j}^{t}-\dot{\varepsilon}_{i j}^{p}$.

$$
\begin{aligned}
& \frac{D s_{i j}}{D t}=2 \mu\left(\dot{\varepsilon}_{i j}^{e}-\frac{1}{3} \dot{\varepsilon}_{k k}^{e} \delta_{i j}\right) \\
& \dot{P}=-K \dot{\varepsilon}_{k k}^{e}
\end{aligned}
$$

where

$$
\begin{aligned}
& \sigma_{i j}=\left(-P \delta_{i j}+s_{i j}\right) \\
& \frac{D s_{i j}}{D t}=\dot{s}_{i j}-s_{i k} \dot{\omega}_{j k}-s_{j k} \dot{\omega}_{i k} \\
& \dot{\varepsilon}_{i j}=\frac{1}{2}\left(\dot{u}_{i, j}+\dot{u}_{j, i}\right) \\
& \dot{\omega}_{i j}=\frac{1}{2}\left(\dot{u}_{i, j}-\dot{u}_{j, i}\right)
\end{aligned}
$$


$\dot{\varepsilon}_{k k e}^{e}$ is the rate of volumetric strain, $\mu$ is the shear modulus, $K$ is the bulk modulus, $P$ is pressure, $s_{i j}$ are the components of deviator stress tensor, $\frac{D}{D t}$ means the co-rotational Jaumann time derivative, $\dot{\omega}_{i j}$ are the components of the rotation strain rate tensor.

The aim of the constitutive equations of the second group is the definitions of rates of inelastic strains in the Eq. (5)-(6). Here the components of inelastic strain rate are identified according to the theory of plasticity. The model of DruckerPrager-Nikolaevskiy with non-associated flow law is taken as a basis allowing for describing the dilatation and internal friction processes independently. The limiting surface of stresses is written down in the form of Drucker-Prager

$$
f=\frac{\alpha}{3} J_{1}+J_{2}^{1 / 2}-Y=0
$$

where $f$ is the yield surface and $J_{1}, J_{2}$ are the first and the second invariants of the stress tensor and $Y$ is the current strength. In the case of non-associated flow rule the plastic potential $g\left(\sigma_{i j}\right)$ does not coincide with a function of plasticity and according to Nikolaevskiy is written as follows [15]:

$$
g\left(\sigma_{i j}\right)=J_{2}+\frac{\Lambda}{3} J_{1}\left(2 Y-\frac{\alpha}{3} J_{1}\right)+\text { const }
$$

Here $\Lambda$ is the dilatancy coefficient.

Components of rates of inelastic strains will be defined as follows:

$$
\begin{aligned}
& \dot{\varepsilon}_{i j}^{p}=\dot{\lambda} \frac{\partial g}{\partial \sigma_{i j}} \\
& \dot{\varepsilon}_{i j}^{p}=\left(s_{i j}+\frac{2}{3} \Lambda\left(Y-\frac{\alpha}{3} J_{1}\right) \delta_{i j}\right) \dot{\lambda}
\end{aligned}
$$

where $\dot{\lambda}$ is the plasticity multiplier in the theory of plasticity.

The peculiarities of the boundary value problem statement in the case of tectonic flow modeling are presented in $[9,10]$. In the case of modeling the state of stress and strain in the geological profiles the boundary conditions correspond to the collisional process and are schematized in Fig. 6. Loading is carried out in two stages. At the first stage, the "task of bringing to equilibrium" is solved when the force of gravity alone acts. At the second stage, tectonic stresses are added, namely, compression along the profile.

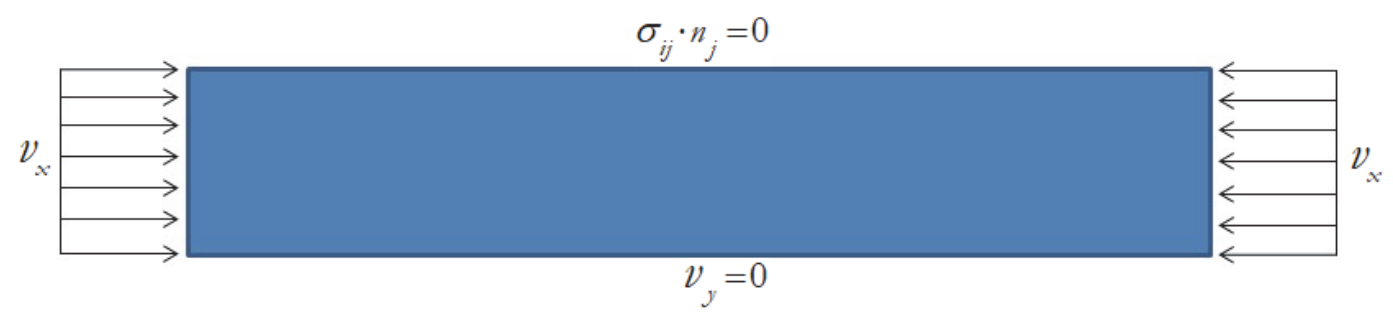

Figure 6: Schematic of the boundary conditions for the geological profiles to model the collisional process.

To analyze the stress state type we use the Lode parameter determined by the formula

$$
\mu_{\sigma}=2 \frac{S_{2}-S_{3}}{S_{1}-S_{3}}-1
$$

where $S_{1}, S_{2}, S_{3}$ are the main values of the deviatoric stress tensor.

The numerical implementation is carried out according to the Wilkins finite-difference method [16]. 


\section{RESULTS}

L

oading features of the chosen geological objects that govern the stress state type are determined from the calculations of tectonic flows in Central and Southeast Asia. These calculations are made with consideration only for collisional processes of the Eurasian Plate with the Indian and Arabian plates in the south and with the North American Plate in the northeast. The modeling results are presented in Fig. 7.

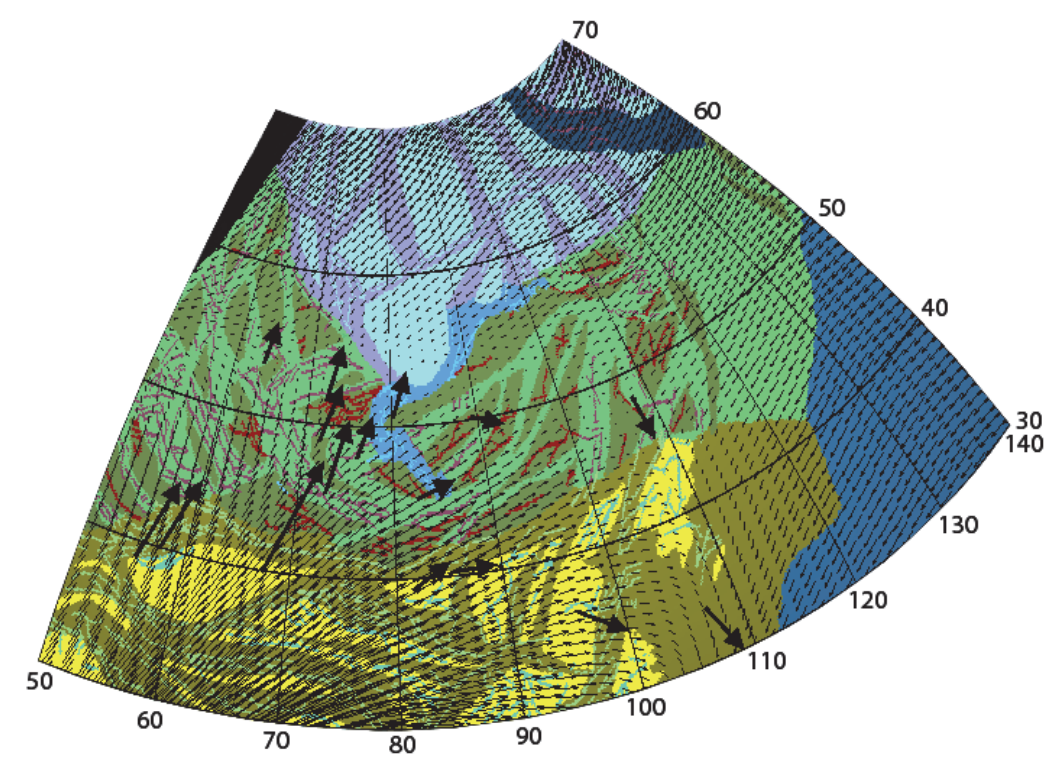

Figure 7: Modeled tectonic flows relative to the city of Irkutsk as compared to the observational data.

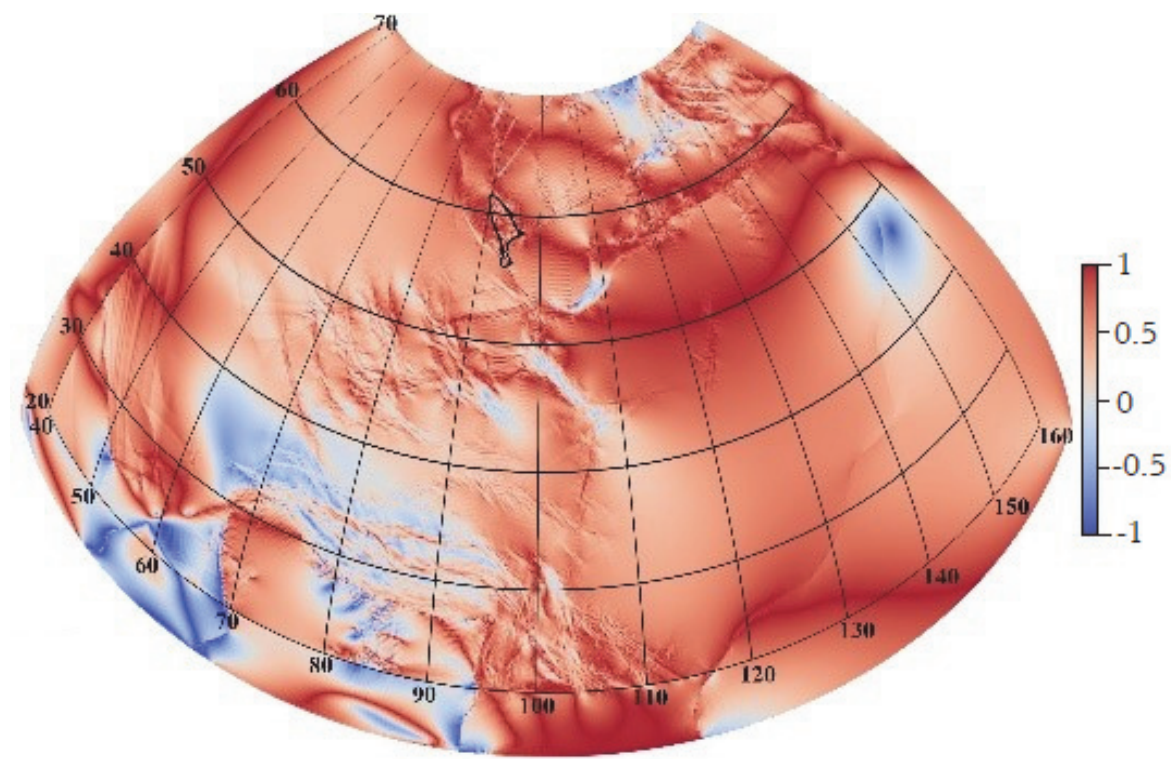

Figure 8: Stress state type by the Lode parameter in Central and Southeast Asia.

The analysis of the performed calculations shows that compression-shear combinations predominate in the Yenisei Ridge. These calculations reflect pulses transmitted from collisional regions and inducing only the displacement of the studied objects as whole. Subtracting the average translational motion from the displacement vectors drastically changes the local flow pattern. Of great importance is the point in the studied area relative to which the flow is considered. Figure $9(\mathrm{a}, \mathrm{b})$ 
details the calculated stress state type as well as displacement fields that are plotted relative to these regions and reflect regional directions of the geomedium flow in the Yenisei Ridge.

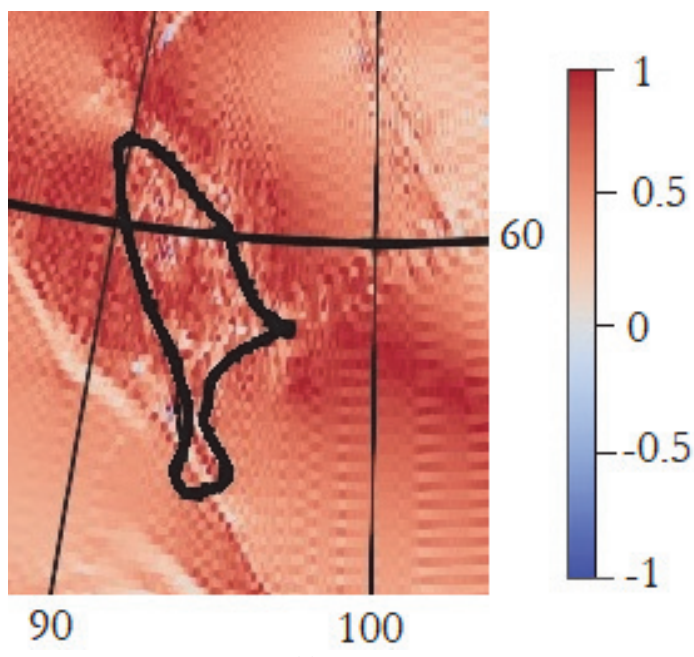

(a)

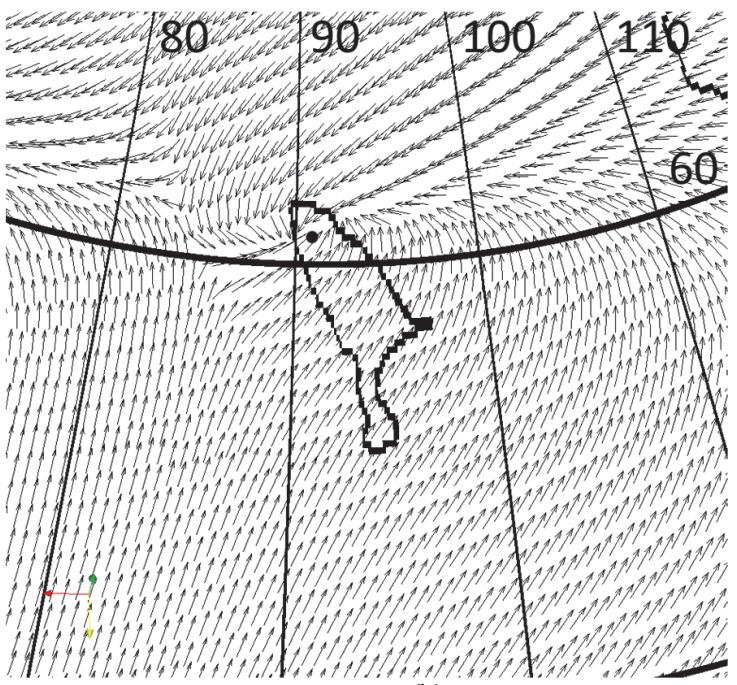

(b)

Figure 9: Modeling results of tectonic flows and the stress state in the Yenisei Ridge: (a) the stress state type by the Lode parameter and (b) displacement fields defined relative to the marked point.

The calculations of tectonic flows also demonstrate that the compression direction in the Yenisei Ridge is perpendicular to the Yenisei shear belt [5], and the Batolit-1982 and Shpat geological profiles lie in the compression direction. Consequently, strain can be calculated along the Batolit-1982 and Shpat profiles under loading by compression along the profile.

The modeled distribution of plastic strains is shown in Fig. 10.

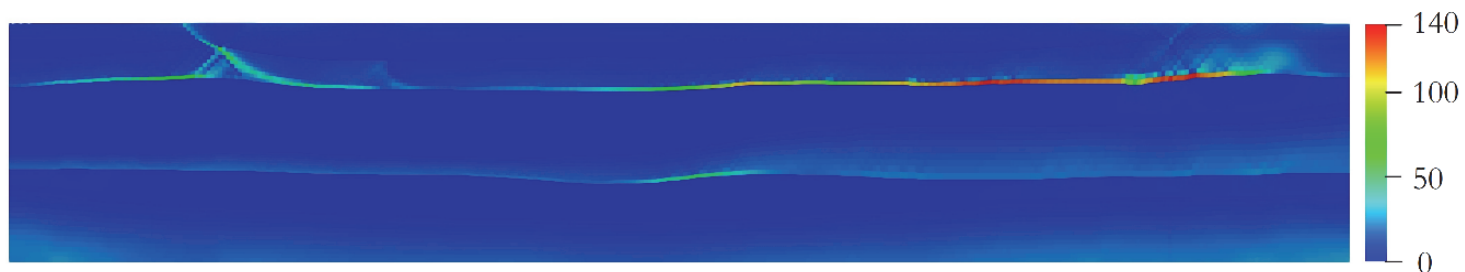

(a)

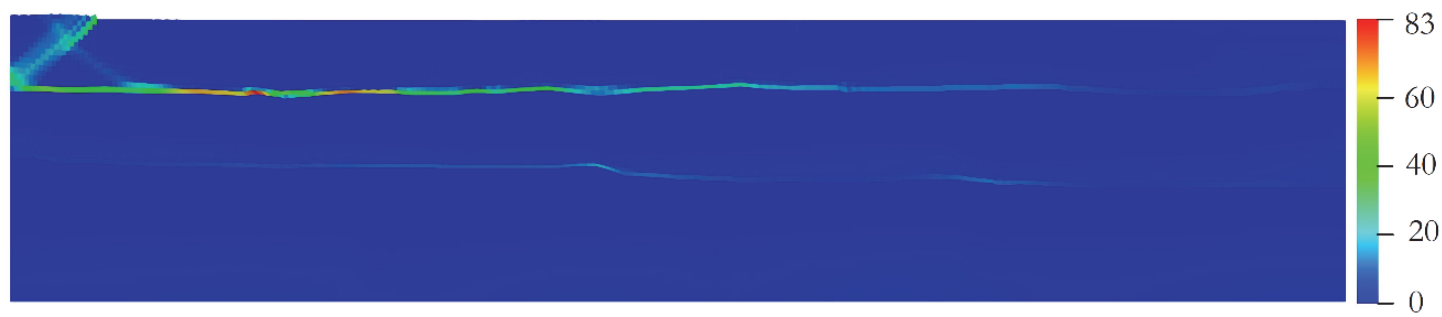

(b)

Figure 10: Distribution of plastic strains (\%) in the Yenisei Ridge along the (a) Batolit-1982 and (b) Shpat profiles.

The analysis of the presented results gives the following findings. The presence of faults determines initiation sites of inelastic deformation and further development of localized deformation. The main factors responsible for initiation sites of inelastic deformation and propagation of localized deformation bands are fault zones and curvature of interfaces between the layers. The orientation of localized deformation bands is influenced by internal friction and dilatancy, which enter the Drucker-Prager-Nikolaevskii plasticity law. Figure 10 shows that in both cases the strain localizes in the Yenisei shear belt, which is located in the upper left part of the figures.

Distributions of horizontal and shear stresses are presented in Figs. 11 and 12. 


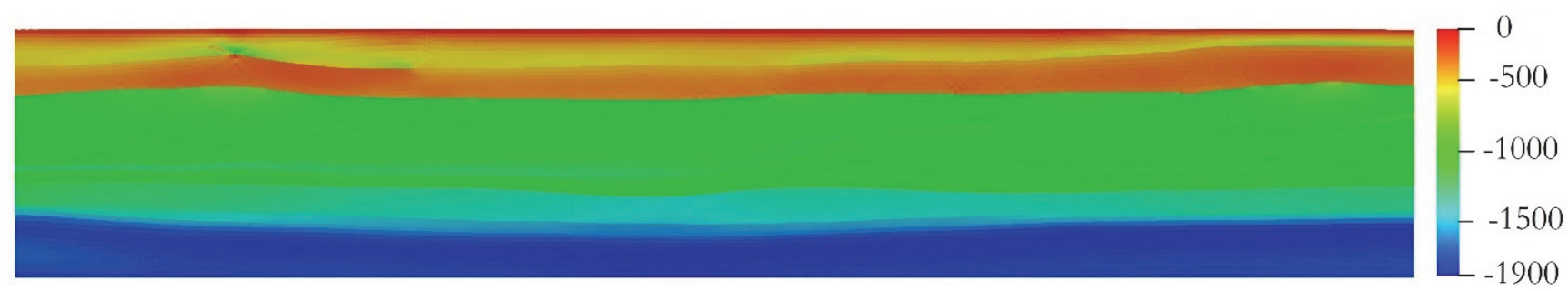

(a)

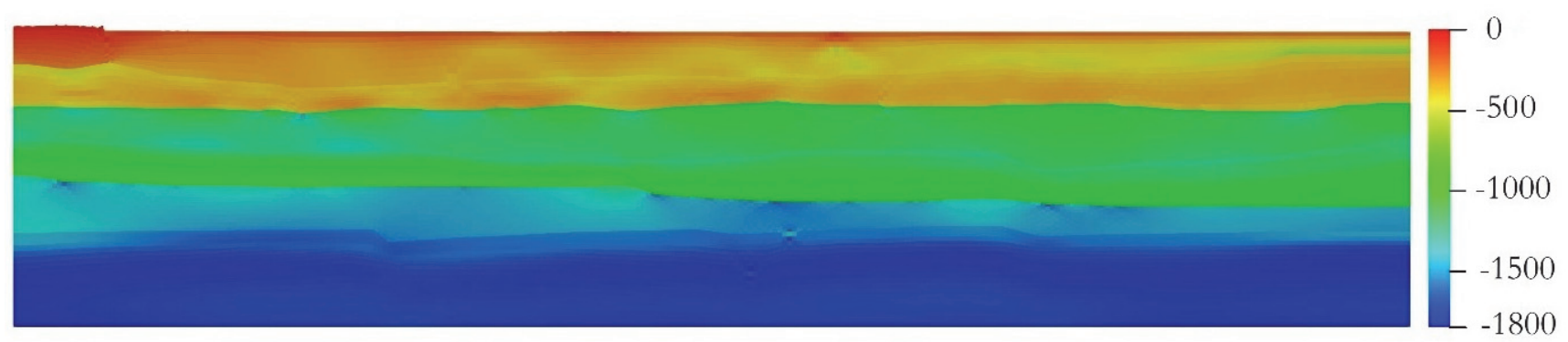

(b)

Figure 11: Distribution of horizontal stresses $(\mathrm{MPa})$ in the Yenisei Ridge along the (a) Batolit-1982) and (b) Shpat profiles.

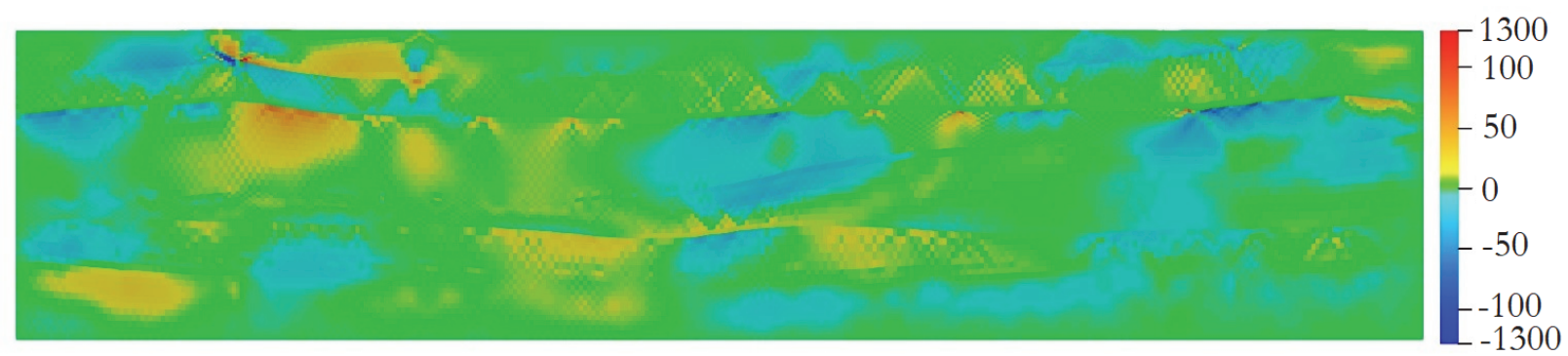

(a)

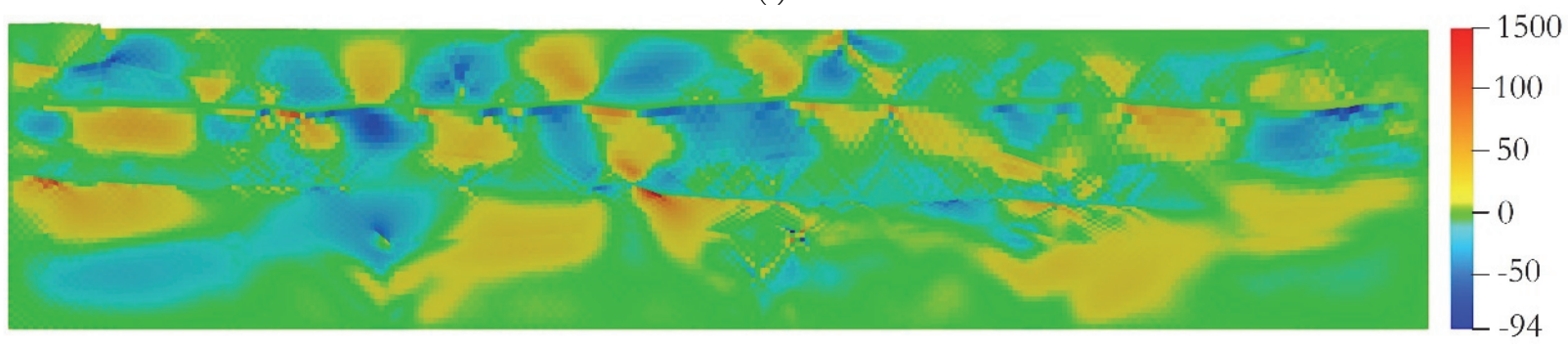

(b)

Figure 12: Distribution of shear stresses (MPa) in the Yenisei Ridge along the (a) Batolit-1982 and (b) Shpat profiles.

These results demonstrate the following special features. Distribution of horizontal stresses is determined by the strength changing in the crustal layers. Distribution of shear stresses depends to a great extent on the accumulated inelastic strain.

\section{CONCLUSIONS}

e evaluated the stress state type in the Siberian Craton, specifically in the Yenisei Ridge located to the southwest of the Siberian Craton. To do this, we solve the problem of calculation of tectonic flows and the related stress state type in Central and Southeast Asia caused by the collision with the Indian and Arabian 
plates in the south and the North American Plate in the northeast. These calculations allowed plotting displacements of the Siberian Craton as a whole, calculating its local deformation, and determining a deformation pattern of the Yenisei Ridge in particular. The calculations also showed that compression-shear combinations predominate in the Yenisei Ridge. The calculations of the depth distributions of stress and strain in the Yenisei Ridge along the Shpat and Batolit-1982 geological profiles disclosed that the main factors determining nucleation sites of inelastic deformation and propagation of localized deformation bands are fault zones and curvature of interfaces between the layers. For both profiles the plastic deformation distribution reveals deformation localization in the Yenisei shear belt.

\section{ACKNOWLEDGMENTS}

his work was supported by the Russian science foundation, grant No. 19-17-00122.

\section{REFERENCES}

[1] Wegener, A. (1966). The Origin of Continents and Oceans. Dover, New York.

[2] Replumaz, A., Capitanio F.A., Guillot S., Negredo A.M., Villasenor A. (2014). The coupling of Indian subduction and Asian continental tectonics, Gondwana Research, 26, pp. 608-626. DOI: 10.1016/j.gr.2014.04.003

[3] Lobkovsky, L.I. (2016) Deformable plate tectonics and regional geodynamic model of the Arctic region and Northeastern Asia, Russian Geology and Geophysics, 57, pp. 371-386. DOI: 10.1016/j.rgg.2016.03.002

[4] Cherepanova, Yu., Artemieva, I.M., Thybo, H., Chemia, Z. (2013) Crustal structure of the Siberian craton and the West Siberian basin: An appraisal of existing seismic data, Tectonophysics, 609, pp. 154-183. DOI: $10.1016 /$ j.tecto.2013.05.004

[5] Likhanov, I.I., Regnier, J.-L., Santosh, M. (2018) Blueschist facies fault tectonites from the western margin of the Siberian Craton: Implications for subduction and exhumation associated with early stages of the Paleo-Asian Ocean, Lithos, 304-307, pp. 468-488. DOI: 10.1016/j.lithos.2018.02.021

[6] Vernikovsky, V.A., Metelkin D.V., Vernikovskaya, A.E., Matushkin, N.Yu., Kazansky, A.Yu., Kadilnikov, P.I., Romanova, I.V., Wingate, M.T.D., Larionov, A.N., Rodionov, N.V. (2016) Neoproterozoic tectonic structure of the Yenisei Ridge and formation of the western margin of the Siberian craton based on new geological, paleomagnetic, and geochronological data, Russian Geology and Geophysics, 52, pp. 24-39. DOI: 10.1016/j.rgg.2010.12.003

[7] Domeier, M. (2018) Early Paleozoic tectonics of Asia: Towards a full-plate model, Geoscience Frontiers, 9, pp. 789862. DOI: $10.1016 /$ j.gsf.2017.11.012

[8] Müller, R.D., Qin, X., Sandwell, D.T., Dutkiewicz, A., Williams, S.E., Flament, N., Maus, S., Seton, M. (2016) The GPlates Portal: Cloud-Based Interactive 3D Visualization of Global Geophysical and Geological Data in a Web Browser, PLOS ONE, 11(3), pp.1-17. DOI: 10.1371/journal.pone.015088

[9] Makarov, P.V., Peryshkin, A.Yu. (2016) Mathematical model and numerical simulation of slow deformation in the earth's crust structural elements, AIP Conference proceedings, 1783, 020146. DOI: 10.1063/1.4966439.

[10] Peryshkin, A.Yu., Makarov, P.V., Eremin, M.O. (2014) Numerical simulation of tectonic plates motion and seismic process in Central Asia, AIP Conference proceedings, 1623, pp. 487-490. DOI: 10.1063/1.4898988.

[11] Seminskii, K.Zh (2008) Hierarchy in the zone-block lithospheric structure of Central and Eastern Asia, Russian Geology and Geophysics, 49, pp.771-779. DOI: 10.1016/j.rgg.2007.11.017

[12] Burov, E.B. (2011) Rheology and strength of the lithosphere, Marine and petroleum Geology, 28, pp. 1402-1443. DOI: $10.1016 /$ j.marpetgeo.2011.05.008.

[13] Goetze, C., Events, B. (1979) Stress and temperature in bending lithosphere as constrained by experimental rock mechanics, Geophys. J.R. Astr. Soc., 59, pp. 463-478.

[14] Kozlovsky, Ye.A. (1987) The Superdeep Well of the Kola Peninsula, Berlin, Springer Verlag.

[15] Nikolaevskiy, V.N. (1996) Geomechanics and Fluidodynamics with Applications to Reservoir Engineering, Kluwer, Dordrecht.

[16] Wilkins, M.L. (1999) Computer Simulation of Dynamic Phenomena, Springer-Verlag, Berlin. 